\section{Executive functions of interns after a night on call}

\section{Funções executivas em residentes após plantão noturno}

\section{Dear Editor,}

Executive function (EF) is a set of cognitive abilities which permit the start of activities, planning, programming and sequencing of actions ${ }^{1}$. Medical residency is generally acknowledged to be stressful, and thus interns are susceptible to fatigue and chronic sleep deprivation given their prolonged work hours and rotating work schedules ${ }^{2}$. The importance of this question is illustrated by the increasing public and academic attention focused on the role of resident physicians' fatigue in the occurrence of medical errors, percutaneous needle sticks, laceration injuries and post-on-call motor vehicle crashes ${ }^{3,4}$. A limit of 80 work hours per week was instituted in the USA in $2003^{5}$, but even with this regulation many studies have identified problems during residency. We aimed to compare the executive functions of Brazilian first-year internal medicine residents after a night on call in the emergency room (ER) and after a night off duty during training using neuropsychological tests. The study was approved by the Ethics Committee of the Hospital Central da Irmandade da Santa Casa de Misericórdia de São Paulo (process number 074/04). Thirty-eight out of the 40 first-year internal medicine residents agreed to participate and gave written informed consent.

Exclusion criteria were as follows: substance abuse (alcohol or drugs); current use of medication known to affect the sleep/ wake cycle or daytime alertness; neurological disease; attention deficit/hyperactivity disorder; lifetime history of traumatic brain injury/vascular brain disorder; severe, uncompensated sensory loss (deafness, muteness, or blindness); and participation in another medical residency program in the previous year. We included both residents during a normal shift at an internal medicine ward and residents who had not been on a night call for at least $72 \mathrm{~h}$.

The neuropsychological tests ${ }^{1}$ used and the cognitive functions assessed are presented in Table1. The assessments were performed for each resident twice in the morning immediately after the night on call (stage 1) and the night off duty (stage 2). There were at least eight weeks between the first and second evaluations. Differences between stages were tested with Wilcoxon test. Tests were twotailed and results were considered significant when $\mathrm{p}<0.05$.

After a night on call, residents showed worse inhibitory control of impulses in the Stroop Color Test W ( $\mathrm{p}=0.029)$ and the Interference Effect Stroop ( $\mathrm{p}=0.007)$ than after a night off duty. In addition, also after a night on call, the residents had more perseverative errors in the Wisconsin Card Sorting Test $(p=0.028)$, showing worse cognitive flexibility (Table 1$)$.

We recognize that it is difficult to design a study to evaluate the clinical implications of cognitive deficits. Therefore, we designed a study that combined several features. Importantly, we sampled a homogeneous group of doctors, relatively young, without previous work experience, who were their own controls (stage 2) and subject to the same workload, with the same number of working hours per week including night shifts (60h: work hour limit in Brazil) in contrast to those in many studies 5 . Our results highlight an issue that could be of interest to educators involved in training residents when planning their educational programs.

Table 1 - Cognitive performance of internal medicine residents after Stage 1 and Stage 2 ( $n=38$ )

\begin{tabular}{|c|c|c|c|}
\hline \multirow{2}{*}{ Neuropsychological tests } & Stage1 & Stage 2 & \multirow[b]{2}{*}{$p$-values } \\
\hline & Mean (SD) & Mean (SD) & \\
\hline Stroop Color Test D (seconds) ${ }^{*}$ & $16.38(7.057)$ & $16.78(12.767)$ & 0.381 \\
\hline Stroop Color Test W (seconds)* & $17.95(7.721)$ & $18.84(14.990)$ & 0.242 \\
\hline Stroop Color Test C (seconds)* & $23.54(7.225)$ & 22.49(11.994) & 0.029 \\
\hline Interference Effect Stroop ** & $6.02(4.63)$ & $3.48(8.06)$ & 0.007 \\
\hline WCST - perseverative errors & $1.87(4.938)$ & $0.45(1.224)$ & 0.028 \\
\hline WCST - failure to maintain set & $0.11(0.388)$ & $0.16(0.437)$ & 0.608 \\
\hline
\end{tabular}




\section{Acknowledgements}

The authors thank all of the internal medicine residents for their participation in this study, as well as Gislaine Gil and Fabiana Tintori for performing the neuropsychological tests.

Aida Cristina Suozzo

Emergency room of Hospital Central da Irmandade da Santa Casa de Misericórdia de São Paulo (ISCMSP), Department of Psychiatry and Medical Psychology, School of Medical Science of Santa Casa de Misericórdia de São Paulo (FCMSCSP)

Stella Maria Malta

Interdisciplinary Clinical Neurosciences Laboratory, Department of Psychiatry, Universidade Federal de São Paulo

(UNIFESP)

Ricardo Asensio Rodriguez Institute of Psychiatry of Hospital das Clínicas da Faculdade de Medicina da Universidade de São Paulo (HCFMUSP)
Eliane Villar

Institute of Psychiatry of Hospital das Clínicas da Faculdade de Medicina da Universidade de São Paulo (HCFMUSP)

Luiz Antonio Nogueira-Martins

Department of Psychiatry, Universidade Federal de São Paulo

(UNIFESP)

\section{Disclosures}

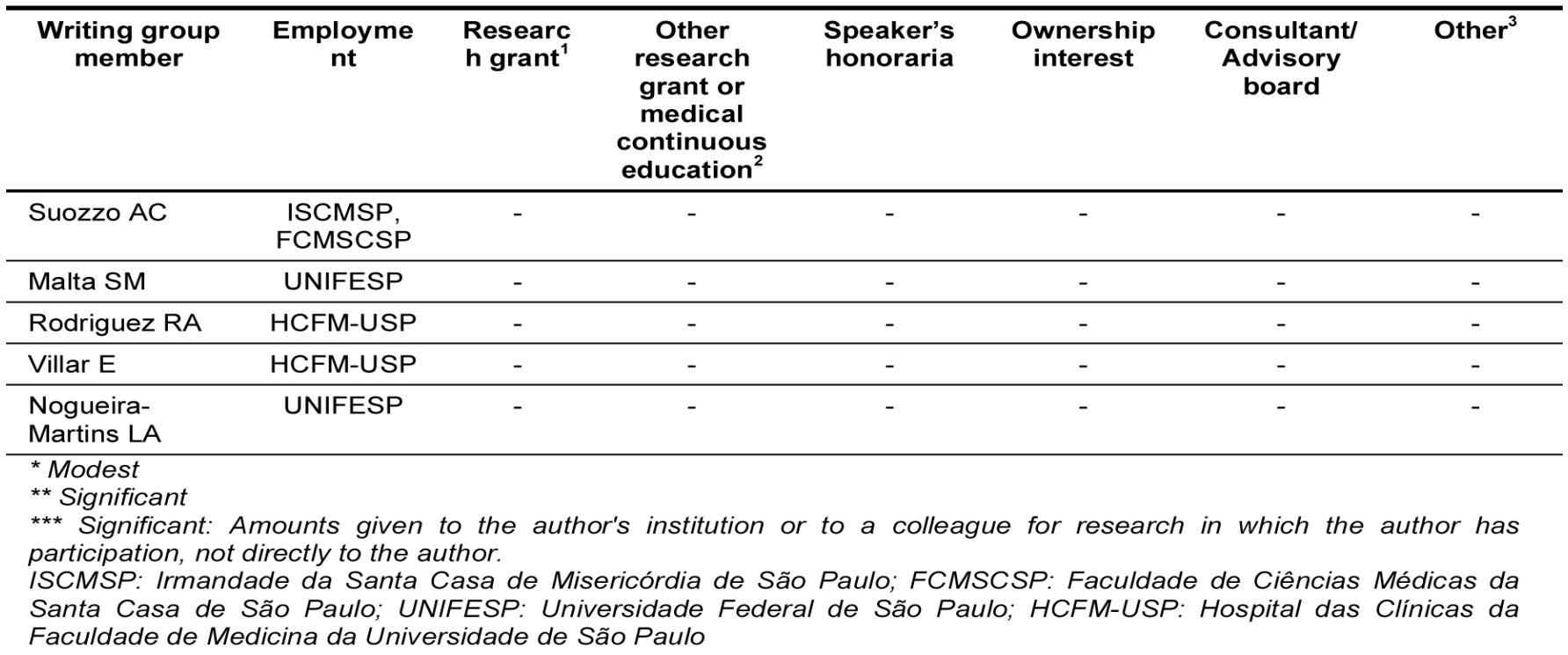

References

1. Spreen O, Strauss EA. A compendium of neuropsychological tests: administration, norms and commentary. New York (NY): Oxford University Press; 1998.

2. Rosen IM, Gimothty PA, Shea JA, Bellini LM. Evolution of sleep quantity, sleep deprivation, mood disturbances, empathy, and burnout among interns. Acad Med. 2006; 81:82-5.

3. Szklo-Coxe M. Are residents' extended shifts associated with adverse events? PLoS Med. [serial on the Internet] 2006 [cited 2010 Nov 10]; 3(12):e497. Available from: URL: http://www.plosmedicine.org
4. Barger LK, Ayas NT, Cade BE, Cronin JW, Rosner B, Speizer FE, Czeisler CA Impact of extended duration shifts on medical errors, adverse events and attentional failures. PLoS Med. 2006;3:e487.

5. National Academy of Sciences. Residency duty hours: enhancing sleep, supervision and safety. 2009. [on line] [Cited 2010 Nov 10]. Available from: URL: http://www.nap.edu/catalog/12508.html 